\title{
The calculation of the allowable diametrical inaccuracy of the cycloidal driving bores in a cycloidal drive with a given profile error and transmission ratio fluctuation
}

Attila Csobán ( $\nabla$ dr.csoban.attila@gmail.com )

Budapest University of Technology and Economics

\section{Original Article}

Keywords: transmission ratio fluctuation, profile error, diametrical inaccuracy, manufacturing accuracy of transmissions

Posted Date: May 4th, 2021

DOI: https://doi.org/10.21203/rs.3.rs-370301/v1

License: (c) (i) This work is licensed under a Creative Commons Attribution 4.0 International License. Read Full License 


\title{
ORIGINAL ARTICLE // OPEN ACCESS
}

\section{The calculation of the allowable diametrical inaccuracy of the cycloidal driving bores in a cycloidal drive with a given profile error and transmission ratio fluctuation}

\author{
Attila Csobán
}

\begin{abstract}
Cycloidal drives are getting more and more widespread due to their beneficial properties. The greatest advantage of these transmissions compared to other general-purpose industrial transmissions, but even compared to the more widespread types of planetary gears, is their ability to operate with large transmission ratios and good efficiency under larger performance density. A smaller amount of play and the minimal fluctuation of transmission ratios, which fundamentally define the kinematic properties of these high precision premium transmissions, can only be achieved by increasing the manufacturing accuracy, decreasing the magnitude of manufacturing errors and limiting the tolerance field. The current research, has focused on finding the allowable manufacturing accuracy of transmissions that are primarily manufactured by small scale or by one-off production, and discusses the effect of the cycloidal driving bores diametrical inaccuracy in a cycloidal disc, that was manufactured with wire electrical discharge machining and contains profile defects.
\end{abstract}

Keywords: transmission ratio fluctuation; profile error; diametrical inaccuracy; manufacturing accuracy of transmissions

\section{Introduction}

The investigation of the manufacturing defects' effect on the kinematic properties was performed assuming different levels of manufacturing inaccuracy and tolerance fields on the various tooth geometries. The required minimum accuracy for a given tooth geometry, which guarantees a predefined maximal transmission ratio fluctuation, can be defined from the obtained results. In order to solve the geomerical equations that define the connection, numerical methods and a software specifically written for this task were used. The magnitude of manufacturing defects was defined based on given tolerance fields in order to define the kinematic properties.

The definition of the transmission ratio fluctuation, that was caused by manufacturing defects, was done numerically for different gear geometries and for different cycloidal driving bores. The results show that the transmission ratio changes as a function of the rotation angle of the drive shaft. Based on the maximum

Correspondence: csoban.attila@gt3.bme.hu

Department of Machine and Product Design, Budapest University of

Technology and Economics, Müegyetem rkp. 3., Budapest, HU

Full list of author information is available at the end of the article transmission ratio fluctuation for a given module, profile defect and number of teeth and by using a derived analytical approximation, the required manufacturing accuracy for the dimensions of the cycloidal driving bores can be predicted for a given maximum transmission ratio inaccuracy $[1,2]$.

\section{Production failures}

In the main components of drives with cycloidal crogs, diameter failures of the pitch-circle may occur, there can be distribution failures, profile failures, diameter failures of driving bores or hit failures of the rolling circle, but hit failures of the planetary gear are also possible due to an excentrity failure $[3,4]$.

Equations made to find out how profile failures affect transmission can be solved by applying numerical methods, in case of this research in a Scilab environment. Earlier, when the connection between profile failures and transmission fluctuation was examined, it could be proved that transmission is not constant and it varies around the figure without any failures. Furthermore, the curve depicting trans-mission change is not continous $[3,4]$. The reason for that is that there 
is only one cog pair connection due to the failure and the connected cog pairs vary during the motion of the planetary gear. Where the curve is interrupted, the former cog pairs leave the connection and the motion will be determined by the following $\operatorname{cog}$ pair. Consequently, each section of the curve belongs to different cog pairs[1,2].

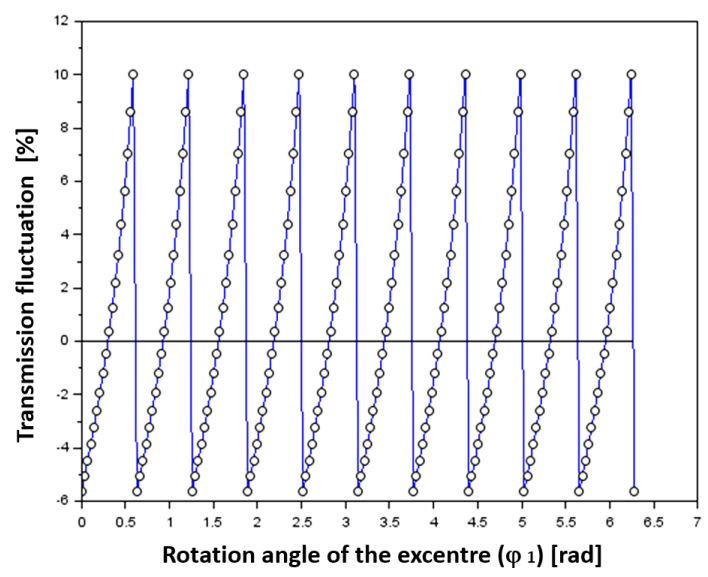

Figure 1 Transmission fluctuation expressed in percentage

\section{Consideration of failures of driving bores}

It has been proved by previous researches and measurements that backlash is developed by profile failure because the input shaft has to rotate so that a cog pair hits while the planetary gear is not rotating. In this chapter, backlash resulting from the diameter failure of driving bores $(\Delta d)$ is also described in addition to the backlash generated by profile failures [] .

In this figure, backlash resulting from profile failures are marked with $\varphi_{0}$ and backlash caused by a diameter failure of a driving bore is marked as $(\Delta f)$. After the input shaft rotates by $\varphi_{0}$, a $\operatorname{cog}$ pair will already be connected. After it keeps turning, the planetary gear will also rotate. In order to cause the output shaft to rotate as well, the driving pin has to hit (it is marked with an interrupted line in figure 2). The shaft rotation needed to enable this hit is marked as $\Delta \varphi$.

In this chapter, the rotation angle $\Delta \varphi$ is determined for a gear with different cog numbers. In case of both gears with the given $\operatorname{cog}$ numbers, the grade of the profile failure has been defined in advance determining the tolerance zone resulting from the diameter of the pitch-circle of the planetary gear and the particular accuracy level. Like in case of profile failures, driving bore failures have been estimated in due consideration of the tolerance zones applicable to the different accuracy levels.

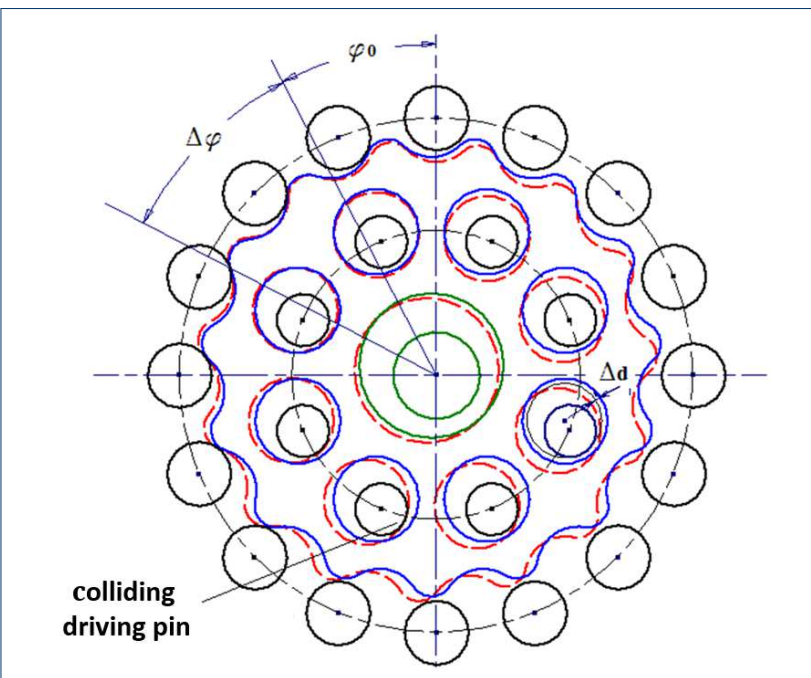

Figure 2 Backlash resulting from the failure of driving bores

\section{Equations}

In order to define the rotation angle needed for the hit of a driving pin $[5,6]$, we can establish the geometrical equations according to the following figure:

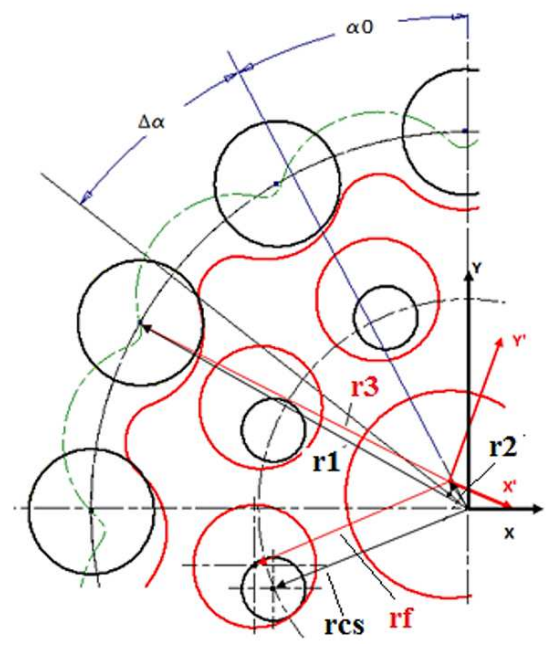

Figure 3 Applicable equations

According to the equation describing the connection of two cog pairs:

$$
r=T \cdot r_{3(\varphi)}+r_{2\left(\varphi_{1}\right)}
$$


where: $r_{1}$ is the vector pointing at the center of the connected pin, $T$ is the transformation matrix, $r_{3(\varphi)}$ is the vector containing the parameter equations describing the shifted curve in the coordinate system $X^{\prime} Y^{\prime}, \varphi$ is the parameter of the equations describing the curve, $r_{2}\left(\varphi_{1}\right)$ - is the vector pointing at the center point of the planetary gear, $\varphi_{1}$ is the angle determining the location of the excenter, $\varphi_{2}\left(\varphi_{1}\right)$ - is the rotation angle of the planetary gear.

The transformation matrix:

$$
T=\left[\begin{array}{cc}
\cos \left(\varphi_{2}\right) & \sin \left(\varphi_{2}\right) \\
-\sin \left(\varphi_{2}\right) & \cos \left(\varphi_{2}\right)
\end{array}\right]
$$

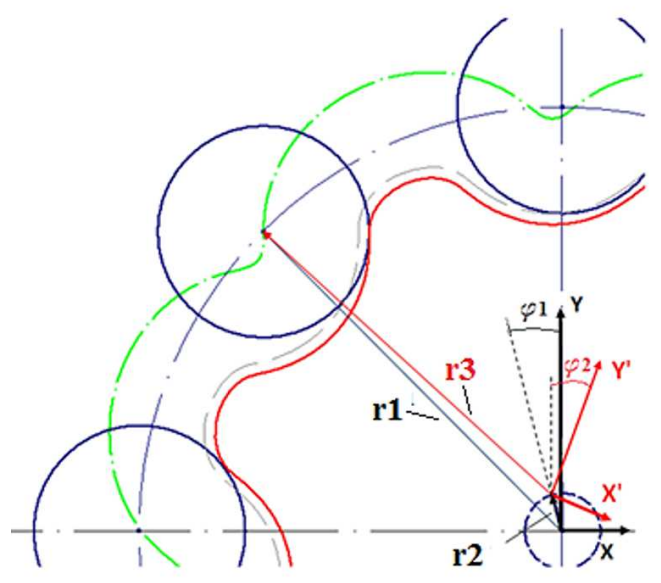

Figure 4 Determination of the rotation angle of the planetary gear

Besides, the following connection (equation) can be established when the driving bore and the driving pin come into contact:

$$
\left|r_{2}+r_{f}-r_{c s}\right|=e+\Delta d
$$

where: $r_{f}$ is the vector pointing at the center of the driving bore, $r_{c s}$ is the vector pointing at the centerpoint of the colliding driving pin, $e$ is excentrity (axial distance), $\Delta d$ is the diameter failure of the driving bore.

After solving the above-mentioned equations, we receive the figures of $\varphi_{1}=\Delta \varphi, \varphi_{2}, \varphi$ where the driving pin hits $[5,6]$. The process diagram of the algorhytm of the calculation:

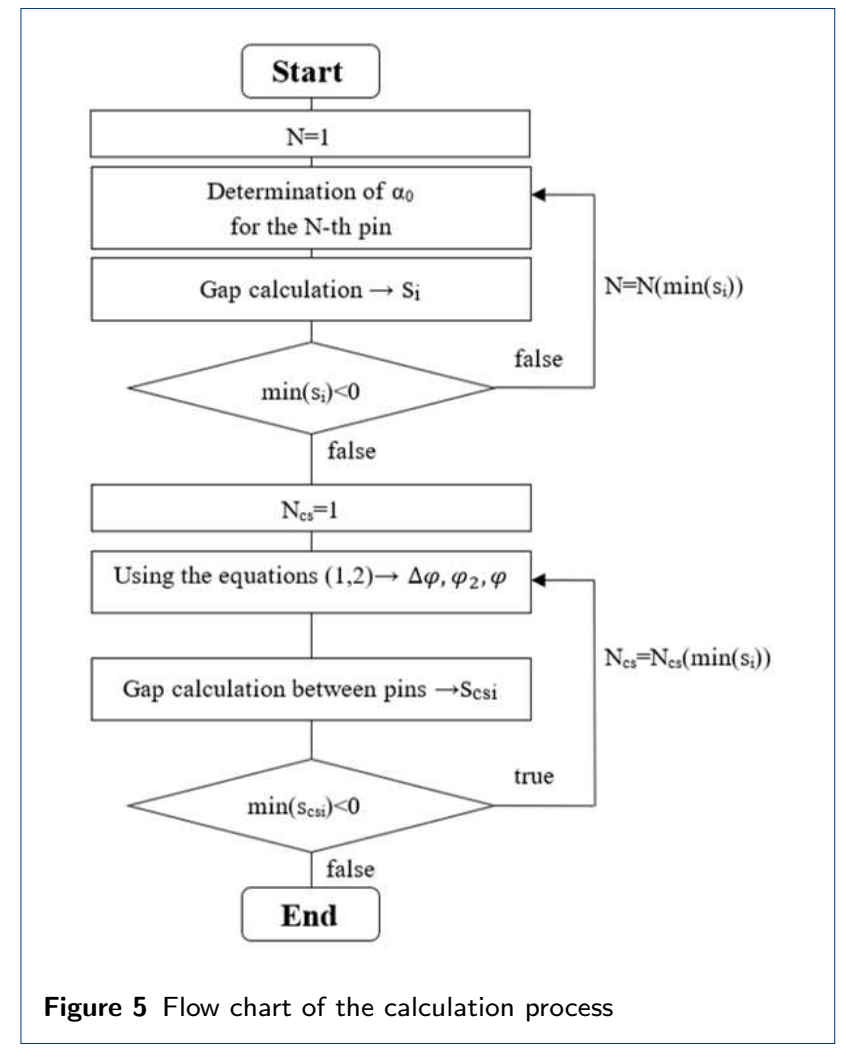

where the used marks: $\alpha$ is the rotation angle of the excentre required for the collosion, $N$ is the number of the connected pins, $N_{c s}$ is the number of the driving pins, $s_{i}$ is the gap calculated at the pin i, $s_{c s i}$ is the gap between the driving pin and the driving bore, $N_{(\min (s i))}$ is the number of pins defined for the minimum gap, $N_{c s(\min (s i))}$ is the number of the driving pin with the smallest gap, $\varphi_{1}$ is the rotation angle of the excentre $\left(\varphi_{1}=\varphi_{0} \ldots \varphi_{n}\right), \varphi_{2}$ is the rotation angle of the planetary gear, $\Delta \varphi_{1}$ is the grade of the rotation angle of the excenter.

\section{Examined geometries}

Calculations have been performed for two gear geometries.

Table 1 Common parameters of the gears.

\begin{tabular}{|l|l|}
\hline Module $(m):$ & $3[\mathrm{~mm}]$ \\
\hline Addendum modification $(x):$ & $0.25[-]$ \\
\hline Generating circle radius factor $\left(r_{c}^{*}\right):$ & $1[-]$ \\
\hline Number of the driving pins $\left(N_{c s}\right):$ & $8[-]$ \\
\hline Diameter of the driving pins $\left(d_{c s}\right):$ & $20[\mathrm{~mm}]$ \\
\hline Diameter of the driving bores $\left(d_{f}\right):$ & $22.25[\mathrm{~mm}]$ \\
\hline Number of teeth ring gear $\left(z_{2}=z_{1}+1\right):$ & $10[-]$ \\
\hline $\begin{array}{l}\text { Bolt circle diameter of the driving bore } \\
\text { and the driving pins }(D):\end{array}$ & $80[\mathrm{~mm}]$ \\
\hline
\end{tabular}


Gears differ from each other in terms of the cog number, for the first gear $z_{1}=43$ and for the other gear $z_{1}=50$ (figure 6 ).
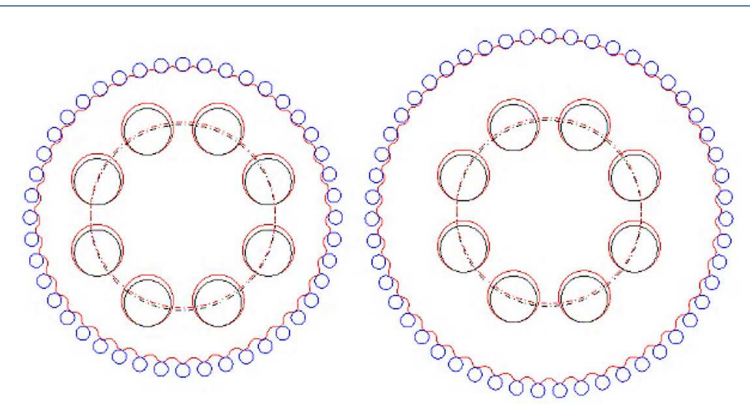

Figure 6 Gears with the following cog number: $z_{1}=43$ and $z_{1}=50$

The following chart shows the diameter of the pitchcircle of the gears $d_{z=43}=126[\mathrm{~mm}]$ and $d_{z=50}=$ $150[\mathrm{~mm}]$, and the profile failures which are assigned to these figures.

Table 2 Profile failures in case of $m=3[\mathrm{~mm}]$

\begin{tabular}{|c|c|c|c|c|c|}
\cline { 2 - 6 } \multicolumn{1}{c|}{} & \multicolumn{5}{c|}{ Profile Error } \\
\cline { 2 - 6 } \multicolumn{1}{c|}{} & IT5 & IT6 & IT7 & IT8 & IT9 \\
\hline$z_{1}=43$ & 0.0065 & 0.0095 & 0.0125 & 0.0125 & 0.018 \\
\hline$z_{2}=43$ & 0.0105 & 0.015 & 0.02 & 0.02 & 0.0285 \\
\hline
\end{tabular}

Table 3 Diameter error of driving bores

\begin{tabular}{|c|c|c|c|c|}
\hline \multicolumn{5}{|c|}{ Profile error } \\
\hline IT5 & IT6 & IT7 & IT8 & IT9 \\
\hline 0.0045 & 0.0065 & 0.0105 & 0.0165 & 0.026 \\
\hline
\end{tabular}

\section{Results}

The $\Delta \varphi$ rotation angle figures resulting from the calculation are summarized in the following charts. The findings are shown in the following diagrams. The results are indicated depending on profile failures and the diameter failures of the driving bores. A surface has been fitted to the points using the method of the smallest squares. It is also depicted.
Results in case of a cog number of $z_{1}=43$ :

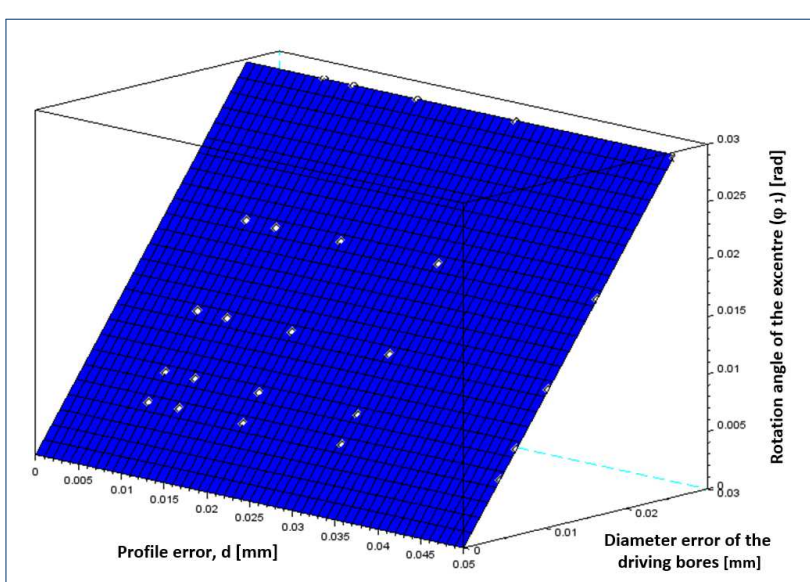

Figure 7 Rotation angle figures in case of $z_{1}=43$

Equation applicable to the surface fitted to the points:

$$
\Delta \varphi=1.1437 \cdot \Delta d-7686 \cdot 10^{-4} \cdot \Delta d \cdot d
$$

where: $\Delta d$ is the diameter failure of the driving bore, $\mathrm{d}$ is a profile error.

Results in case of a cog number of $z_{1}=50$ :

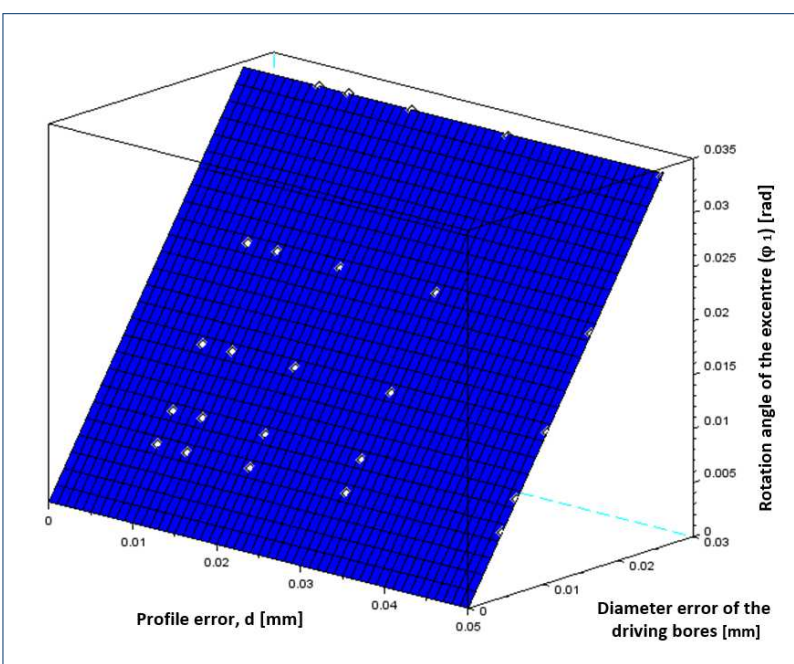

Figure 8 Rotation angle figures in case of $z_{1}=43$

Equation applicable to the surface fitted to the points:

$$
\Delta \varphi=1.3273 \cdot \Delta d-8458 \cdot 10^{-4} \cdot \Delta d \cdot d
$$


Based on the findings, rotation angle varies linearly depending on the diameter failures of the driving bore $(\Delta d)$ while it is not so remarkable depending on the profile failures $(d)$.

Table 4 Diameter error of driving bores

\begin{tabular}{|l|l|l|l|l|}
\hline \multicolumn{1}{|c|}{ Parameter } & \multicolumn{4}{|c|}{ Value } \\
\hline $\begin{array}{l}\text { Number of teeth planet- } \\
\text { gear }\left(z_{1}\right)\end{array}$ & 21 & 59 & 105 & 143 \\
\hline $\begin{array}{l}\text { Number of teeth ring-gear } \\
\left(z_{2}\right)\end{array}$ & 22 & 60 & 106 & 144 \\
\hline Gear ratio $(i)$ & 21 & 59 & 105 & 143 \\
\hline Module $(m)[\mathrm{mm}]$ & 1.5 & 1.5 & 1.5 & 1.5 \\
\hline Pin radius factor $\left(r_{c}^{*}\right)$ & 1 & 1 & 1 & 1 \\
\hline Pin radius $\left(r_{c}\right)[\mathrm{mm}]$ & 1.5 & 1.5 & 1.5 & 1.5 \\
\hline Face width $(b)[\mathrm{mm}]$ & 1.65 & 4.5 & 7.95 & 10.8 \\
\hline $\begin{array}{l}\text { Min. addendum modifica- } \\
\text { tion }\left(x_{m i n}\right)\end{array}$ & 1.65 & 4.5 & 7.95 & 10.8 \\
\hline $\begin{array}{l}\text { Max. addendum modifica- } \\
\text { tion }\left(x_{m a x}\right)\end{array}$ & 0.49 & 0.49 & 0.49 & 0.49 \\
\hline $\begin{array}{l}\text { Chosen addendum modifi- } \\
\text { cation }(x)\end{array}$ & 0.3 & 0.3 & 0.3 & 0.3 \\
\hline $\begin{array}{l}\text { Addendum modification } \\
(X)\end{array}$ & 0.225 & 0.225 & 0.225 & 0.225 \\
\hline Total gear depth $(h)[m m]$ & 1.05 & 1.05 & 1.05 & 1.05 \\
\hline $\begin{array}{l}\text { Planet-gear pitch radius } \\
\left(r_{1}\right)[\mathrm{mm}]\end{array}$ & 15.75 & 44.25 & 78.75 & 107.25 \\
\hline $\begin{array}{l}\text { Ring-gear pitch radius }\left(r_{2}\right) \\
{[m m]}\end{array}$ & 16.5 & 45 & 79.5 & 108 \\
\hline $\begin{array}{l}\text { Centre distance }\left(a_{w}\right) \\
{[m m]}\end{array}$ & 0.525 & 0.525 & 0.525 & 0.525 \\
\hline $\begin{array}{l}\text { Planet-gear working pitch } \\
\text { radius }\left(r_{w 1}\right)[\mathrm{mm}]\end{array}$ & 11.025 & 30.975 & 55.125 & 75.075 \\
\hline $\begin{array}{l}\text { Ring-gear working pitch } \\
\text { radius }\left(r_{w 2}\right)[\mathrm{mm}]\end{array}$ & 11.55 & 31.5 & 55.65 & 75.6 \\
\hline $\begin{array}{l}\text { Driving pin diameter }(d) \\
{[m m]}\end{array}$ & 4 & 11 & 20 & 30 \\
\hline
\end{tabular}

In the following charts, profile failures belonging to a planetary gear with a particular module and cog number are shown. Each chart relates to a particular module and profile failures belonging to different cog numbers (columns) are indicated according to different accuracy levels (rows).

Table 5 Profile failures in case of $m=1[\mathrm{~mm}]$

\begin{tabular}{|c|c|c|c|c|c|}
\cline { 2 - 6 } \multicolumn{1}{c|}{} & $z_{1}$ & 9 & 25 & 43 & 53 \\
\hline \multirow{4}{*}{$I T$} & 5 & 0.003 & 0.0045 & 0.0055 & 0.0065 \\
\cline { 2 - 6 } & 6 & 0.0045 & 0.0065 & 0.008 & 0.0095 \\
\cline { 2 - 6 } & 7 & 0.0075 & 0.0105 & 0.0125 & 0.015 \\
\cline { 2 - 6 } & 8 & 0.011 & 0.0165 & 0.0195 & 0.023 \\
\cline { 2 - 6 } & 9 & 0.018 & 0.026 & 0.031 & 0.037 \\
\hline
\end{tabular}

Table 6 Profile failures in case of $m=2[\mathrm{~mm}]$

\begin{tabular}{|c|c|c|c|c|c|}
\cline { 2 - 6 } \multicolumn{1}{c|}{} & $z_{1}$ & 9 & 25 & 43 & 53 \\
\hline \multirow{4}{*}{$I T$} & 5 & 0.004 & 0.0055 & 0.0075 & 0.0075 \\
\cline { 2 - 6 } & 6 & 0.0055 & 0.008 & 0.011 & 0.011 \\
\cline { 2 - 6 } & 7 & 0.009 & 0.0125 & 0.0175 & 0.0175 \\
\cline { 2 - 6 } & 8 & 0.0135 & 0.0195 & 0.027 & 0.027 \\
\cline { 2 - 6 } & 9 & 0.0215 & 0.031 & 0.0435 & 0.0435 \\
\hline
\end{tabular}

Table 7 Profile failures in case of $m=3[\mathrm{~mm}]$

\begin{tabular}{|c|c|c|c|c|c|}
\cline { 2 - 6 } \multicolumn{1}{c|}{} & $z_{1}$ & 9 & 25 & 43 & 53 \\
\hline \multirow{4}{*}{$I T$} & 5 & 0.0045 & 0.0065 & 0.009 & 0.009 \\
\cline { 2 - 6 } & 6 & 0.0065 & 0.0095 & 0.0125 & 0.0125 \\
\cline { 2 - 6 } & 7 & 0.0105 & 0.015 & 0.02 & 0.02 \\
\cline { 2 - 6 } & 8 & 0.0165 & 0.023 & 0.0315 & 0.0315 \\
\cline { 2 - 6 } & 9 & 0.026 & 0.037 & 0.05 & 0.05 \\
\hline
\end{tabular}

Table 8 Profile failures in case of $m=5[\mathrm{~mm}]$

\begin{tabular}{|c|c|c|c|c|c|}
\cline { 2 - 6 } \multicolumn{1}{c|}{} & $z_{1}$ & 9 & 25 & 43 & 53 \\
\hline \multirow{4}{*}{$I T$} & 5 & 0.0055 & 0.009 & 0.01 & 0.0115 \\
\cline { 2 - 6 } & 6 & 0.008 & 0.0125 & 0.0145 & 0.016 \\
\cline { 2 - 6 } & 7 & 0.0125 & 0.02 & 0.023 & 0.026 \\
\cline { 2 - 6 } & 8 & 0.0195 & 0.0315 & 0.036 & 0.0405 \\
\cline { 2 - 6 } & 9 & 0.031 & 0.05 & 0.0575 & 0.065 \\
\hline
\end{tabular}

In the following charts, transmission fluctuation values are shown (indicated in percentage) assigned to planetary gears with a particular module and cog number. Each chart relates to a particular module and fluctuation figures belonging to different $\operatorname{cog}$ numbers (columns) are indicated according to different accuracy levels (rows).

Table 9 Transmission fluctuation in the case of $m=1[\mathrm{~mm}]$

\begin{tabular}{|c|c|c|c|c|c|}
\cline { 2 - 6 } \multicolumn{1}{c|}{} & $z_{1}$ & 9 & 25 & 43 & 53 \\
\hline \multirow{4}{*}{$I T$} & 5 & 0.406642 & 0.175561 & 0.118517 & 0.112695 \\
\cline { 2 - 6 } & 6 & 0.605794 & 0.251967 & 0.171999 & 0.163288 \\
\cline { 2 - 6 } & 7 & 0.996186 & 0.401931 & 0.265262 & 0.253855 \\
\cline { 2 - 6 } & 8 & 1.439023 & 0.620144 & 0.40575 & 0.380872 \\
\cline { 2 - 6 } & 9 & 2.287451 & 0.950549 & 0.625551 & 0.591149 \\
\hline
\end{tabular}

Table 10 Transmission fluctuation in the case of $m=2[\mathrm{~mm}]$

\begin{tabular}{|c|c|c|c|c|c|}
\cline { 2 - 6 } \multicolumn{1}{c|}{} & $z_{1}$ & 9 & 25 & 43 & 53 \\
\hline \multirow{4}{*}{$I T$} & 5 & 0.272352 & 0.107898 & 0.08165 & 0.065543 \\
\cline { 2 - 6 } & 6 & 0.373185 & 0.156307 & 0.119128 & 0.095636 \\
\cline { 2 - 6 } & 7 & 0.605794 & 0.242469 & 0.187711 & 0.150721 \\
\cline { 2 - 6 } & 8 & 0.899552 & 0.374095 & 0.285666 & 0.229428 \\
\cline { 2 - 6 } & 9 & 1.407824 & 0.584313 & 0.449789 & 0.361376 \\
\hline
\end{tabular}

Table 11 Transmission fluctuation in the case of $m=3[\mathrm{~mm}]$

\begin{tabular}{|c|c|c|c|c|c|}
\cline { 2 - 6 } \multicolumn{1}{c|}{} & $z_{1}$ & 9 & 25 & 43 & 53 \\
\hline \multirow{4}{*}{$I T$} & 5 & 0.20474 & 0.085173 & 0.065468 & 0.052551 \\
\cline { 2 - 6 } & 6 & 0.29482 & 0.124078 & 0.090609 & 0.072736 \\
\cline { 2 - 6 } & 7 & 0.473327 & 0.194754 & 0.143898 & 0.115529 \\
\cline { 2 - 6 } & 8 & 0.737077 & 0.296093 & 0.224108 & 0.179962 \\
\cline { 2 - 6 } & 9 & 1.145266 & 0.469441 & 0.349534 & 0.280764 \\
\hline
\end{tabular}

Table 12 Transmission fluctuation in the case of $m=5[\mathrm{~mm}]$

\begin{tabular}{|c|c|c|c|c|c|}
\cline { 2 - 6 } \multicolumn{1}{c|}{} & $z_{1}$ & 9 & 25 & 43 & 53 \\
\hline \multirow{4}{*}{$I T$} & 5 & 0.150424 & 0.070844 & 0.043778 & 0.040373 \\
\cline { 2 - 6 } & 6 & 0.218288 & 0.098169 & 0.063305 & 0.056021 \\
\cline { 2 - 6 } & 7 & 0.339651 & 0.156307 & 0.099902 & 0.090499 \\
\cline { 2 - 6 } & 8 & 0.526458 & 0.24437 & 0.155164 & 0.139786 \\
\cline { 2 - 6 } & 9 & 0.828283 & 0.3833888 & 0.236076 & 0.22124 \\
\hline
\end{tabular}


Table 13 Rotation angle figures belonging to the cog number: $z_{1}=43$

\begin{tabular}{|c|c|c|c|c|c|c|}
\cline { 3 - 7 } \multicolumn{2}{c|}{} & \multicolumn{5}{c|}{ Driving error of the driving bores } \\
\cline { 3 - 7 } \multicolumn{2}{c|}{} & 0.0045 & 0.0065 & 0.0105 & 0.0165 & 0.026 \\
\hline \multirow{3}{*}{ Profile } & 0.009 & 0.005207 & 0.007513 & 0.012112 & 0.018975 & 0.029765 \\
\cline { 2 - 7 } & 0.0125 & 0.005201 & 0.007505 & 0.012098 & 0.018955 & 0.029735 \\
\cline { 2 - 7 } & 0.002 & 0.005188 & 0.007487 & 0.01207 & 0.018913 & 0.029674 \\
\cline { 2 - 7 } & 0.0315 & 0.00517 & 0.007461 & 0.012029 & 0.018852 & 0.029585 \\
\cline { 2 - 7 } & 0.05 & 0.005143 & 0.007423 & 0.01197 & 0.018763 & 0.029456 \\
\hline
\end{tabular}

Table 14 Rotation angle figures belonging to the cog number: $z_{1}=50$

\begin{tabular}{|c|c|c|c|c|c|c|}
\cline { 3 - 7 } \multicolumn{2}{c|}{} & \multicolumn{5}{c|}{ Driving error of the driving bores } \\
\cline { 3 - 7 } \multicolumn{2}{c|}{} & 0.0045 & 0.0065 & 0.0105 & 0.0165 & 0.026 \\
\hline \multirow{3}{*}{ Profile } & 0.009 & 0.006051 & 0.00873 & 0.01407 & 0.022035 & 0.034545 \\
\cline { 2 - 7 } & 0.0125 & 0.006044 & 0.00872 & 0.014053 & 0.02201 & 0.034508 \\
\cline { 2 - 7 } & 0.002 & 0.006028 & 0.008698 & 0.014019 & 0.021958 & 0.034433 \\
\cline { 2 - 7 } & 0.0315 & 0.006006 & 0.008665 & 0.013968 & 0.021883 & 0.034323 \\
\cline { 2 - 7 } & 0.05 & 0.005972 & 0.008618 & 0.013894 & 0.021772 & 0.034162 \\
\hline
\end{tabular}

The last two charts (table 13 and 14) show the backlash figures of the input shaft resulting from diameter failures of the driving bores and profile failures of the planetary gear. Columns of the charts belong to a particular driving bore failure while rows show the particular profile failures.

\section{Conclusions}

Based on the findings, it is possible to define the production accuracy level of the planetary gear being a core component in case of cycloidal drives in a way that the drive achieves the required kinematic features and the expected dynamics figures. If a particular application field does not require the use of the most accurate drive which does not have any backlash $[7,8]$, it can be prescribed in the planning phase to implement the most cost-effective production technology.

- Based on the findings, it is possible to define the production accuracy level of the planetary gear being a core component in case of cycloidal drives $[9,10]$ in a way that the drive achieves the required kinematic features and the expected dynamics figures.

- If a particular application field does not require the use of the most accurate drive which does not have any backlash, it can be prescribed in the planning phase to implement the most cost-effective production technology.

- Based on the findings, rotation angle varies linearly depending on the diameter failures of the driving bore $(\Delta d)$ while it is not so remarkable depending on the profile failures (d). The results are indicated depending on profile failures and the diameter failures of the driving bores.

\section{Funding}

The research reported in this paper and carried out at BME has been supported by the NRDI Fund (TKP2020 NC, Grant No. BME-NCS) based on the charter of bolster issued by the NRDI Office under the auspices of the Ministry for Innovation and Technology.

Author Information

Attila Csobán, PhD: Assistant professor at Budapest University of Technology and Economics. Member of the As-sociation of Hungarian Inventors since 2000. Member of the Entrepreneurship Council of the Hungarian Research Student Association since 2006. Member of public body of Hungarian Academy of Sciences (MTA) since 2012. Gold level member of the European Who is Who Association since 2013. Research field: gear drives, gearboxes, planetary gear drives, cycloidal drives.

Competing interests

The author declare that he has no competing interests.

\section{Author's contributions}

The paper was written only by Attila Csobán. The author edited and approved the final manuscript.

\section{Acknowledgements}

Hereby, the author would like to express thanks to the engineering student Mr. Dávid Roboz who made a considerable contribution to this research by doing a great job.

\section{References}

1. Chmurawa, M., Lokiec, A.: Distribution of loads in cycloidal planetary gear (cyclo) including modification of equidistant. In: Proceedings of the 16th ADAMS European Mechanical Dynamics Users Conference: 14-15 November 2001; Berchtesgden; Germany (2001). ADAMS user conference

2. Thube, S.V., Bobak, T.R.: Dynamic Analysis of a Cycloidal Gearbox Using Finite Element Method. AGMA, Alexandria, USA (2012)

3. Kumar, N.: Investigation of drive-train dynamics of mechanical transmis-sion incorporating cycloidal drives. PhD thesis, Queensland University of Technology, Department of Mechanical Engineering (2015)

4. B. Borislavov, V.P. I. Borisov: Design of a Planetary-Cyclo-Drive Speed Reducer Cycloid Stage, Geometry, Element Analyses. Hans Hansson, SwePart Transmissions AB, Växjü, Sweden (2012)

5. S.J. Tsai, H.Y.Y. C.H. Huang, Huang, W.J.: Loaded tooth contact analysis of cycloid planetary gear drives. In: Proceedings of the The 14th IFToMM World Congress: 25-30 October 2015; Taipei; Taiwan (2015). IFToMM

6. Yang, D.C.H., Blanche, J.G.: Design and application guidelines for cycloid drives with machin-ing tolerances. Mechanism and Machine Theory 25, 487-501 (1990)

7. Sumitomo: Fine cyclo zero backlash speed reducers. https://emeia.sumitomodrive.com/en-de/fine-cyclo-brand (2021) 
8. nabtesco: Precision reduction gear rv.

http://www.nabtescomotioncontrol.com/pdfs/af-series-brochure2016.pdf (2016)

9. Sumitomo: Cyclo drive 6000 reducer.

https://emeia.sumitomodrive.com/en-de/product/cyclo-drive-6000reducer (2021)

10. Kotec: Roladrive speed reducer. http://www.kotec.com.tw/PDF/KOTECCatalogueCHT.pdf (2016) 
Figures

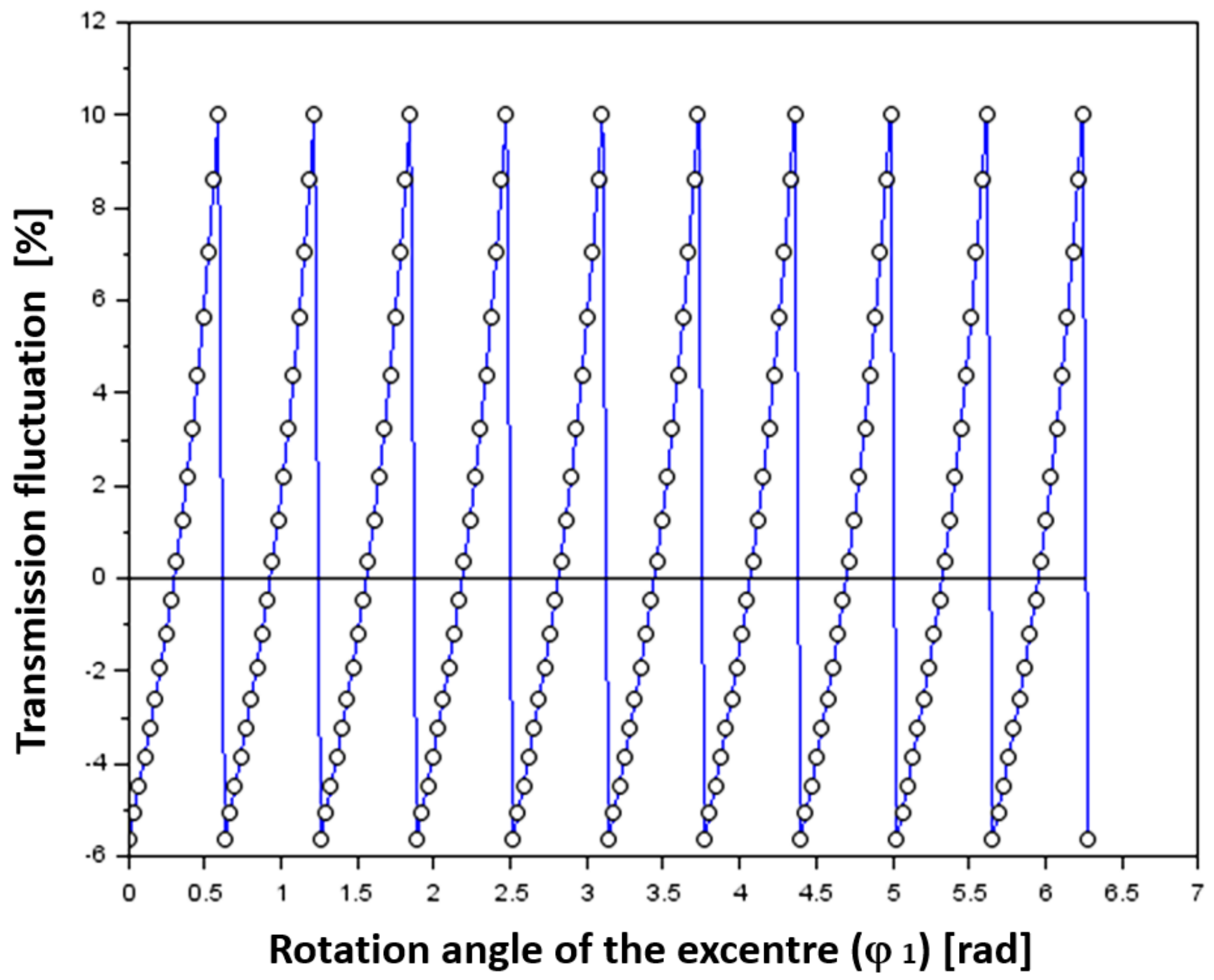

Figure 1

Transmission fluctuation expressed in percentage 


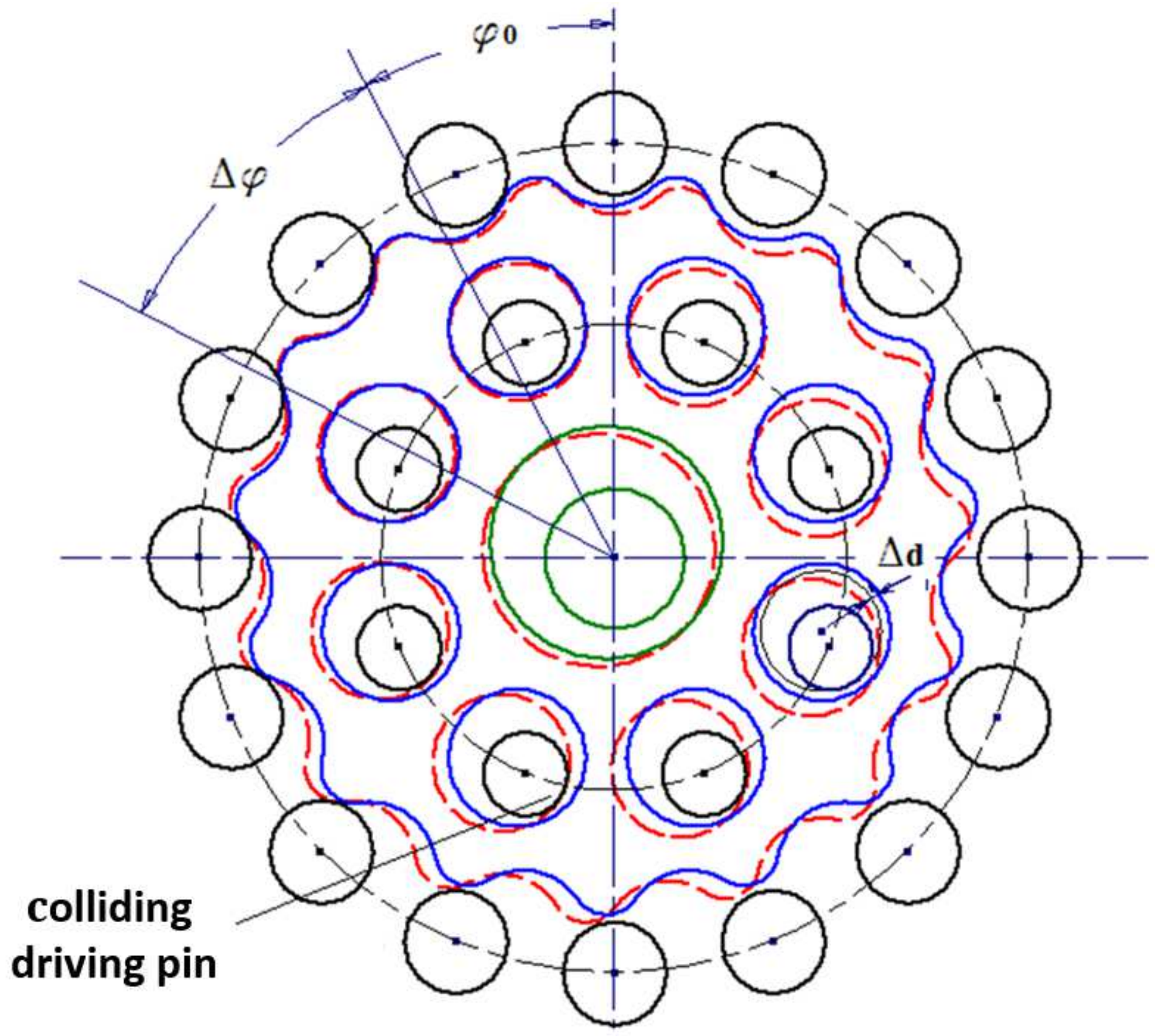

Figure 2

Backlash resulting from the failure of driving bores 


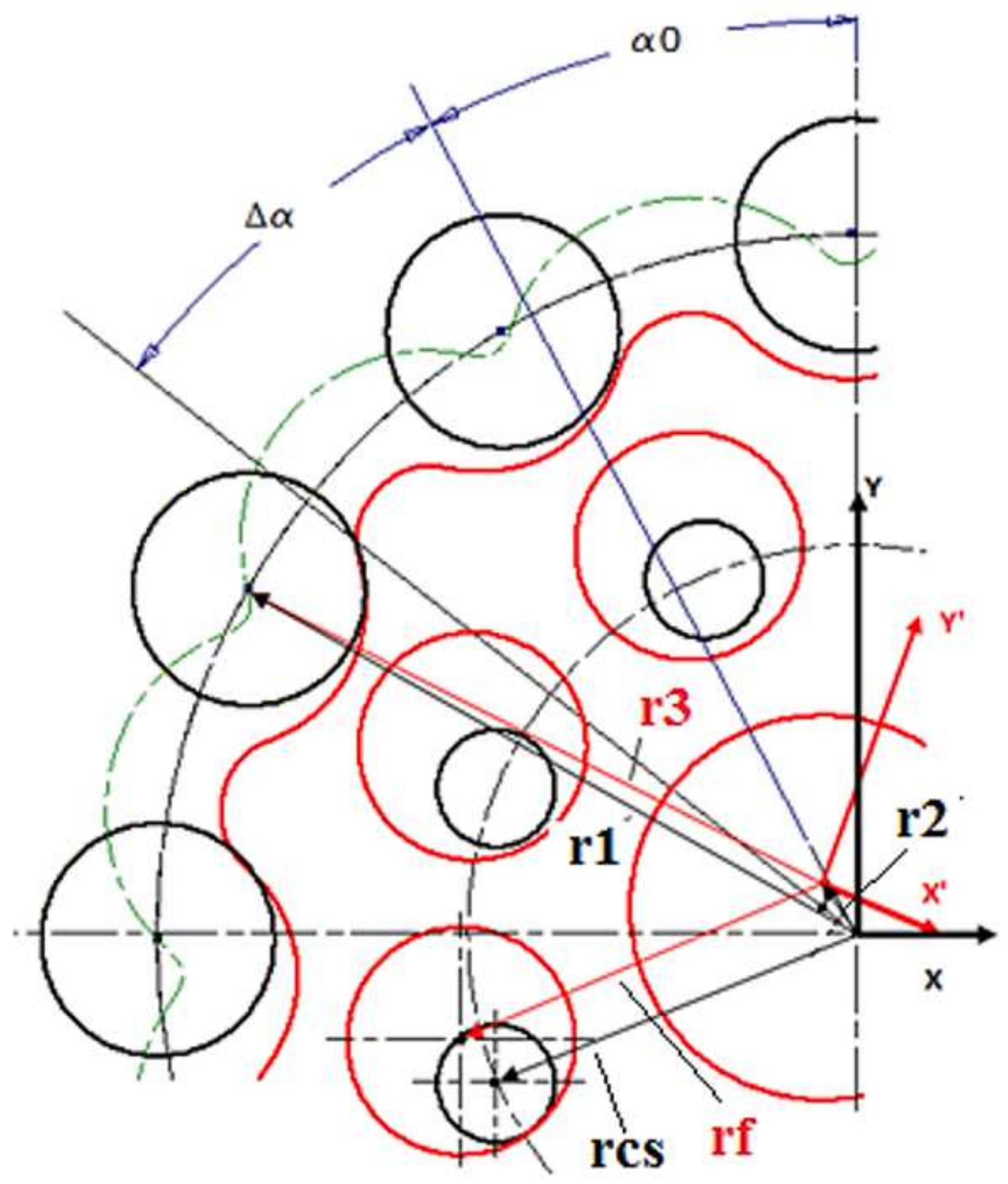

Figure 3

Applicable equations 


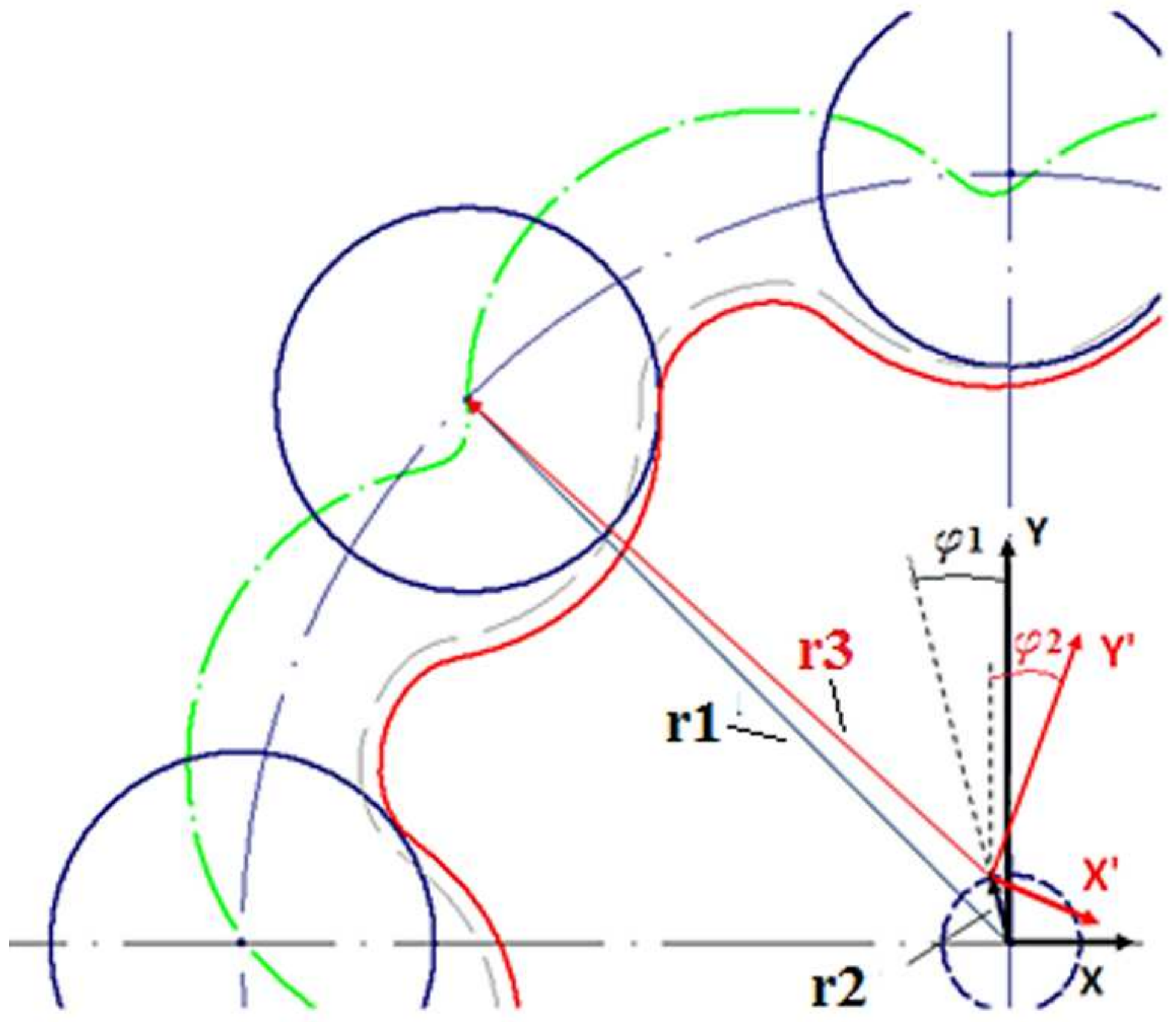

Figure 4

Determination of the rotation angle of the planetary gear 


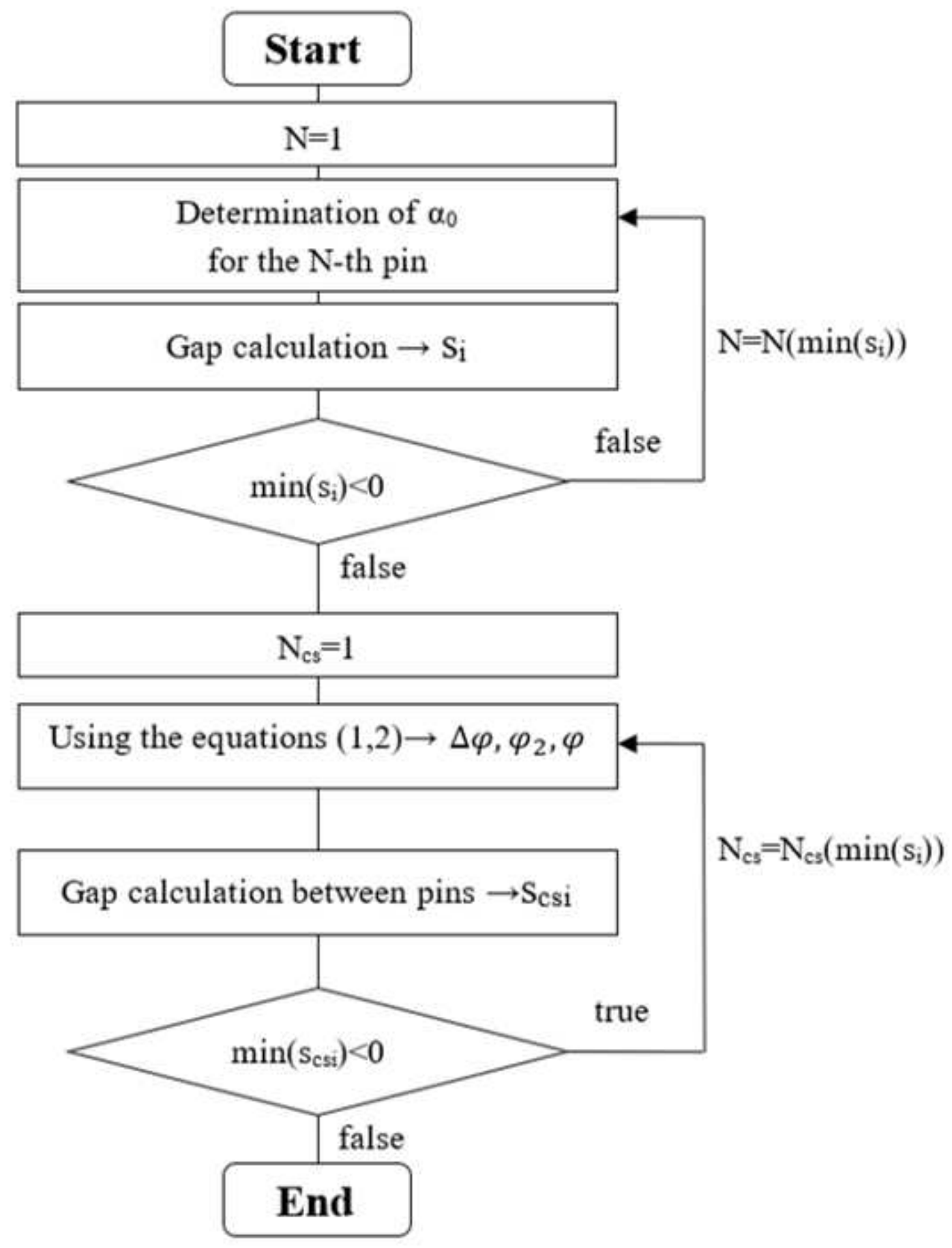

Figure 5

Flow chart of the calculation process 


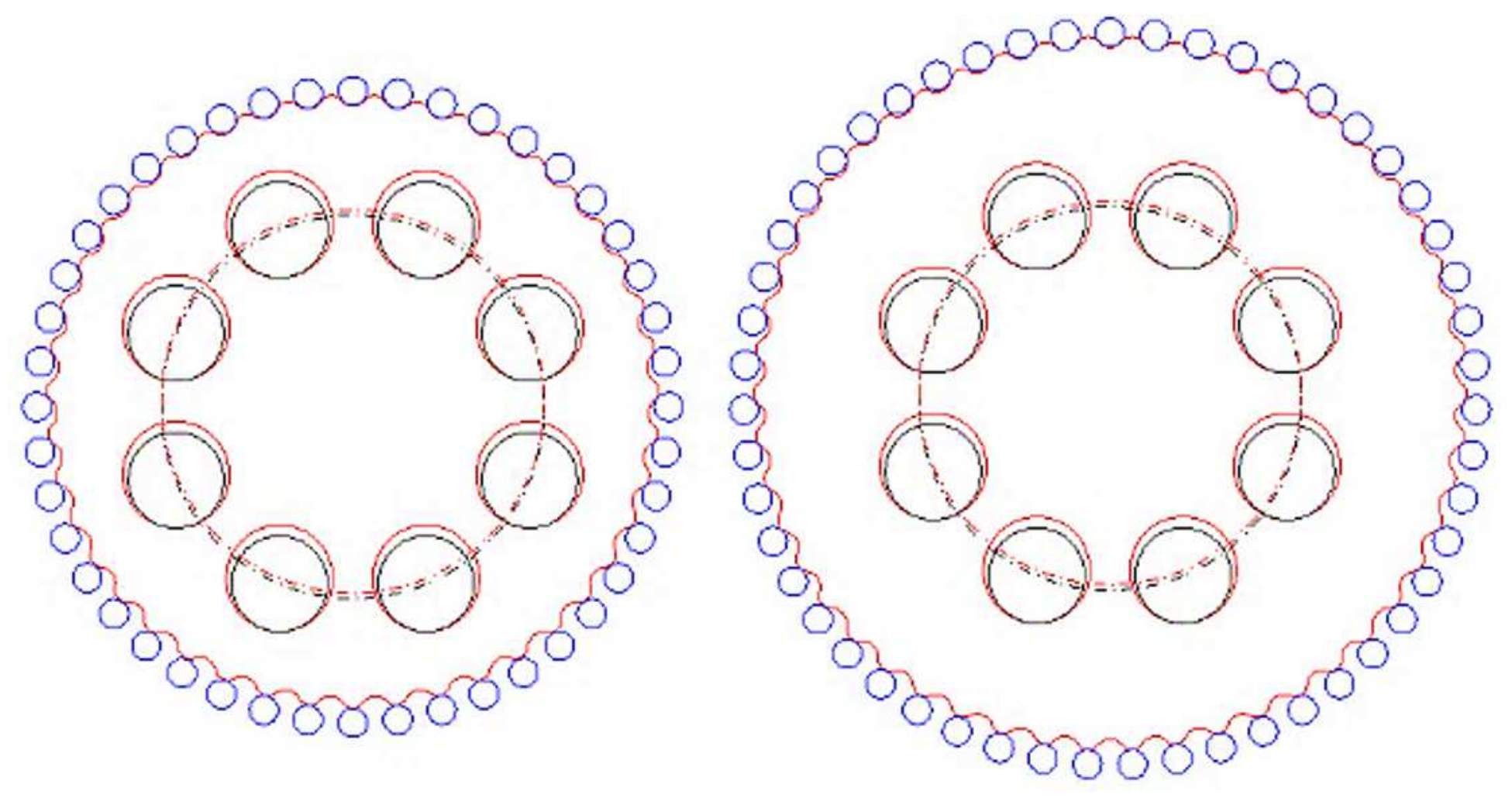

Figure 6

Gears with the following cog number: $z 1=43$ and $z 1=50$ 


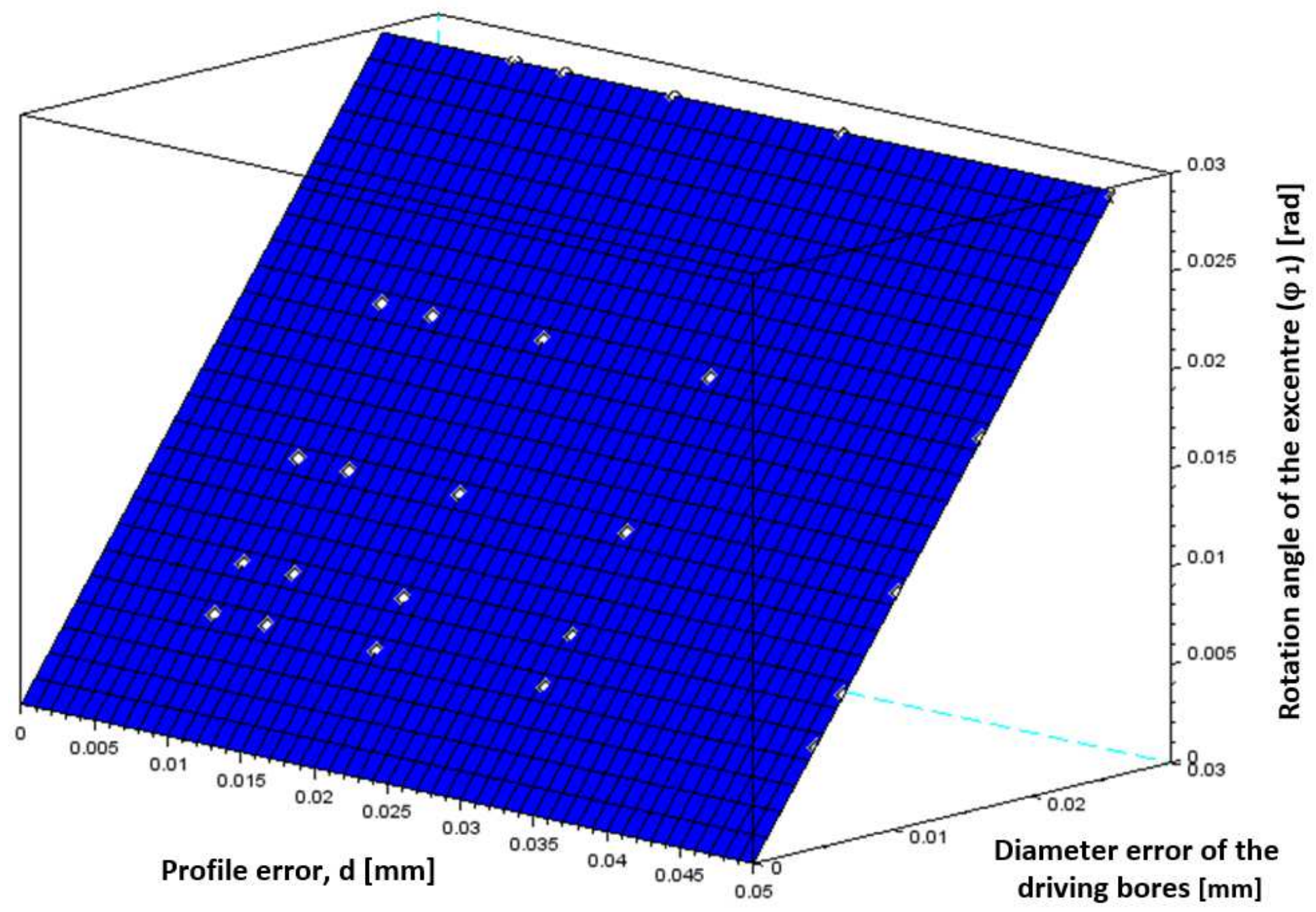

Figure 7

Rotation angle gures in case of $z 1=43$ 


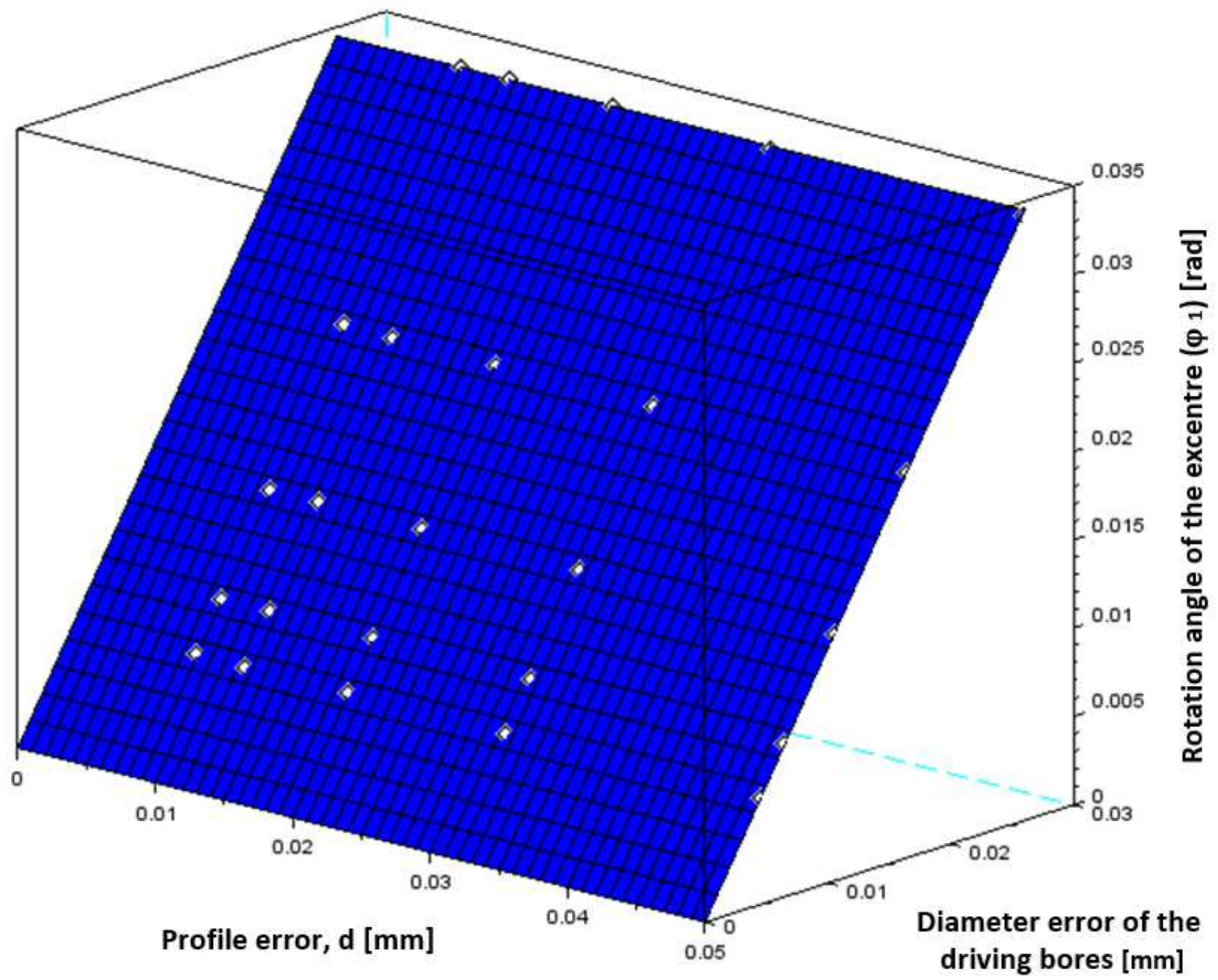

Figure 8

Rotation angle gures in case of $z 1=43$ 